\title{
LOGÍSTICA REVERSA PARA O DESCARTE DE LÂMPADAS
}

\author{
Rodrigo César Silva Rodriguesrodrigo.rodrigues4@alunos.unis.edu.br \\ Ana Beatriz Durães Pinheiro ana.pinheiro1@alunos.unis.edu.br \\ Ingrid Carolina Souza ingrid.souza1@alunos.unis.edu.br \\ Rafael da Silva Augusto rafael.augusto@alunos.unis.edu.br \\ Tiago Bittencourt Nazaré tiago.nazare@professor.unis.edu.br
}

\section{RESUMO}

O consumo de energia elétrica está cada vez mais alto e as pessoas não vivem mais sem ela, porém o problema está no descarte dos produtos, os quais liberam substâncias altamente prejudiciais ao meio ambiente, colocando em risco os ecossistemas e a saúde humana. É fundamental encontrar um método com objetivos e propostas que possam ser desempenhados por todos com o intuito de efetivar a preservação do meio ambiente. A Logística Reversa se trata de um conjunto de ações com o objetivo de viabilizar a coleta e a restituição de resíduos sólidos ao setor empresarial para reaproveitar em seu ciclo ou outra destinação final adequada. Ela acompanha o produto desde a sua venda até o retorno ao seu ponto de origem (os fabricantes), que serão responsáveis pela destinação ambientalmente adequada. Ela contribui também com o lucro da empresa e impõe a responsabilidade pós-consumo aos consumidores. O presente estudo descreve a construção de um método no qual se refere a captação e análise de percepções baseadas em dados estatísticos dos entrevistados por meio de uma amostra aleatória simples. O estudo também traz uma visão de vários autores a respeito do tema abordado, além de obter declarações de empresas e utilização de decretos.

Palavras-chave: Energia Elétrica.Descarte. Pós-Consumo.Meio Ambiente.Logística Reversa.

\section{INTRODUÇÃO}

Em 1879 a energia elétrica chegou ao Brasil e desde então as pessoas ficam cada vez mais dependentes dela. Assim, é notório que cada passar de ano é uma inovação quando diz em relação as lâmpadas. Por outro lado, estamos cada vez mais dependentes desses objetos tecnológicos e, como resultado, o lixo gerado por eles vem aumentando devido ao grande 
consumo e ao encurtamento do ciclo de vida de tais aparelhos, dada a rápida evolução tecnológica e seu consequente aprimoramento.

O conhecimento da Logística Reversa e a educação relacionada ao descarte de lixo eletrônico é precário, tendo em vista que publicidades e diálogos sobre o assunto são ausentes na população, apesar de que autoridades e consumidores já estão mais atentos quando se trata de descarte de lâmpadas em relação ao meio ambiente. Por isso, é preciso estruturar sistemas que atendam as metas impostas pela legislação.

Apesar de algumas empresas já apresentarem soluções para atender os consumidores que desejam descartar seus produtos, as metas impostas pelas leis brasileiras representam um grande desafio a ser encarado. Não só nas entidades, mas como toda a população deve ser reeducada em relação ao descarte correto de lâmpadas, como por exemplo programas governamentais em conjunto com instituições privadas. Porém, o problema está no descarte incorreto de produtos tecnológicos que prejudicam muito o meio ambiente.

Nesse contexto desafiador, entra em cena a importância da Logística Reversa como solução para o problema não só dos descartes de lâmpadas, mas como do lixo eletrônico como um todo. Sendo bem planejada, implementada e conduzida, pode trazer benefícios financeiros, ambientais e sociais. Há diversos países desenvolvidos que vêm obtendo resultados significativos ao implementar a logística reversa. Exemplo disso é a Suíça que apesar de ser um país desenvolvido, ainda está num estágio no processo de implementação.

O presente estudo teve como objetivo, fazer uma revisão bibliográfica, procurando ressaltar a importância do descarte correto de lâmpadas, e, também a aplicação de um questionário com o ótimo objetivo de se fazer os entrevistados entenderem a importância da Logística Reversa.

\section{METODOLOGIA}

Para o presente estudo, foi realizado os métodos da Pesquisa Bibliográfica e da Aplicação de Questionário. Para a pesquisa, através de pesquisas online no Google Books foram feitas leituras em sites governamentais, artigos acadêmicos, utilização de decretos do Sistema Nacional de Informações sobre a Gestão de Resíduos Sólidos (SINIR) e do Ministério do Meio Ambiente (MMA), declaração da empresa VG Resíduos e alguns autores que registraram seus pensamentos a respeito do tema. Entre os autores estão (Alexandre de 
Campos, Douglas Garcia Goulart, Josiane Pichani Lima, Ana Paula Alves, Simone Ludwing, Jaqueline Fernandes Meireles, Alessandra Ribeiro de Moraes, Henrique Manoel Riani Mendes, Nathalia Novaes, Natália Morassi, Manuela Gazzoni dos Passos, Lucas Arno e Diana Folmer).

Em relação ao questionário aplicado através do Google Forms, foi desenvolvido por autoria própria de maneira online, utilizando a Amostra Aleatória Simples, com um prazo de quatro dias para respostas dos participantes. Obteve-se um ótimo retorno com um total de quarenta e oito entrevistados.

Segundo Ochoa (2015), Amostra Aleatória Simples é o método utilizado no qual um grupo de indivíduos são escolhidos aleatoriamente e tem idêntica probabilidade, mantendo sua importância e igualdade no quesito desejado.

Os artigos foram analisados com a finalidade de reunir informações sobre: a logística reversa para o descarte de lâmpadas.

\section{REFERENCIAL TEÓRICO}

\subsection{LOGÍSTICA REVERSA}

Tem sido fundamental nas últimas décadas a preocupação com o impacto dos meios de produção em relação ao meio ambiente. A logística reversa foi criada quando as empresas começaram a demonstrar uma preocupação em relação a utilização dos recursos naturais e com o retorno dos produtos descartados pelos consumidores.

OSistema Nacional de Informações sobre a gestão dos resíduos sólidos (2018)define que: a logística reversa é um processo que ocorre em três etapas básicas e para entender o seu funcionamento, há três processos para o seu funcionamento. $\mathrm{O}$ primeiro passo é quando o consumidor devolve o produto ou embalagem ao distribuidor ou comerciante. Ou seja, onde ele comprou dependendo do tipo de operação realizada. Já o segundo, é quando o comerciante deve remeter ao fabricante ou importador do produto recebido e por sua vez reencaminha o item que foi recepcionado por último para que ele possa ser reutilizado, reciclado ou ainda, tenha o descarte adequado de acordo com o seu material. Além disso a logística reversa pode ser aplicada de dois modos tanto no pós-venda (ocorre quando um erro é detectado ao 
processar o pedido), quanto no pós-consumo (finalização da vida útil, sendo o produto impróprio para o uso). Dessa forma, é descartado corretamente e nada é prejudicado.

\begin{abstract}
A Logística Reversa é um instrumento de desenvolvimento econômico e social caracterizado por um conjunto de ações, procedimentos e meios destinados a viabilizar a coleta e a restituição dos resíduos sólidos ao setor empresarial, para reaproveitamento, em seu ciclo ou em outros ciclos produtivos, ou outra destinação final ambientalmente adequada. (SINIR, 2018).
\end{abstract}

Segundo a ideia de Campos e Gourlart (2017), a logística reversa pode ser relacionada como uma poderosa estratégia competitiva, porque antes os produtos eram simplesmente descartados no meio ambiente, sendo prejudiciais aos seres humanos e ao meio ambiente. Agora passaram a ser reaproveitados e continuam no processo produtivo. Isto torna-se viável por razões econômicas e razões ecológicas, sendo assim o uso de material reciclável aumentando cada vez mais nas empresas, por consequência da sustentabilidade e legislações impostas pelo governo.

A logística se tornou ao longo dos anos um dos fatores determinantes para as empresas quanto à distribuição física dos produtos. Os grandes volumes de transações entre empresas e países, além da necessidade de ter o produto certo, no tempo certo e no local certo, podem garantir o posicionamento das empresas no mercado. Essa área é responsável por todo planejamento, operação e controle do fluxo de mercadorias e informações, desde o fabricante até o cliente final. (CAMPOS E GOULART, 2017).

Segundo o decreto do Ministério do Meio Ambiente (2017):

\begin{abstract}
Fabricantes, importadores, distribuidores e comerciantes que não firmaram termo de compromisso e ficaram fora dos acordos setoriais continuam obrigados a estruturar e implementar sistemas de logística reversa. O governo editou, nesta terça-feira (24/10), o Decreto $n^{\circ}$ 9.177, que regulamenta esta obrigação para a logística reversa na Política Nacional de Resíduos Sólidos. (MINISTÉRIO DO MEIO AMBIENTE,2017).
\end{abstract}

De acordo com MENDES (2017), foram feitas pesquisas relacionadas em comparação de um país com o outro, tendo como exemplo o artigo do país suíço, reconhecido como o primeiro a ser implementado no mundo, além de ser estruturado de forma diferenciada dos 
demais e apresentar um dos maiores índices de coleta de eletroeletrônicos por habitante no mundo. Já no Brasil, empresas e fabricantes de eletroeletrônicos já estão se organizando para estruturar seus sistemas de logística reversa no país, com a ajuda da gestão suíça. A logística reversa não atende somente ao mercado e a economia. Seu principal serviço é o aspecto social e ambiental da sociedade, envolvendo atividades como reciclagem, reaproveitamento de materiais, destinação e tratamento de lixo. É importante ampliar a consciência ambiental como fator determinante na forma de como a sociedade lida com o consumo para garantir a vida das próximas gerações.

\subsection{DESCARTE DE LÂMPADAS}

Ludwing (2018) em relação ao descarte de lâmpadas:

A lâmpada fluorescente foi criada em 1895 pelo Nikola Tesla. É bem eficiente energeticamente. Compõe-se de gases argônio e neônio, que fazem mal para a saúde, podendo causar problemas respiratórios. E ainda um mais nocivo ainda e tóxico, que o fósforo. Altamente cancerígeno. Deve ser descartado de forma adequado para não poluir o meio ambiente. Por exemplo: Se a lâmpada fluorescente quebrou em cima de roupas de cama ou qualquer outro tipo de material que tenha contato direto com o corpo, esta peça não pode mais ser reutilizada, mesmo após lavagem (evite lavar para não contaminar a máquina e a água com mercúrio)! Ela tem que ser descartada, pois o contato com mercúrio já a inutilizou. No caso de se cortar com os cacos de vidro, procure assistência médica o mais rápido possível. (LUDWING, 2018).

Para Lima e Alves (2017):

Embora existam vantagens para o uso das lâmpadas fluorescentes, dentre as quais se destacam a durabilidade e o seu baixo custo, este produto demanda um cuidado maior quando descartado após o término de sua vida útil. Esta atenção origina-se devido à presença do mercúrio em sua composição, mesmo que em quantidade pequena, mas quando somado às outras fontes, pode contaminar o meioambiente e acarretar problemas à saúde. Em contrapartida, o vidro pode ser reaproveitado na fabricação de cerâmicas vitrificadas, fomentando o reuso de matérias-primas, assim como outros subprodutos - alumínio, bases/soquetes, fósforo e até o mercúrio (RECICLUS, 2016). Assim, entende-se que o descarte ambientalmente correto deste produto é fundamental para reduzir impactos ao meio ambiente. (LIMA E ALVES, 2017).

Segundo Novaes e Morassi (2020), atualmente muitas pessoas ainda não sabem fazer o descarte de lâmpadas corretamente e não têm o conhecimento que podem prejudicar o meio 
ambiente podendo contaminar os rios, solos, animais e até mesmo as pessoas. As lâmpadas fluorescentes apresentam um risco maior, pois possuem gases de metais sob pressão no interior do bulbo, como por exemplo o mercúrio (extremamente tóxico e prejudicial à saúde humana e ao meio ambiente).

Analisando todo o ciclo, percebe-se que a questão do descarte correto de lâmpadas é uma questão de consciência, urgência e obrigação. Inclusive, a constituição brasileira prevê na Lei 12.305/10 e em outras leis ambientais, que lâmpadas devem ser descartadas de forma profissional e com responsabilidade ambiental. (NOVES E MORASSI, 2020).

\subsection{LOGÍSTICA REVERSA PARA O DESCARTE DE LÂMPADAS}

VG RESÍDUOS (2018) em relação à logística reversa para o descarte de lâmpadas: as lâmpadas são extremamente perigosas e necessitam de uma destinação adequada após o seu consumo. Quando são descartadas incorretamente, acarretam diversos problemas tais como contaminar o meio ambiente, intoxicar os humanos e podem causar problemas físicos e neurológicos. A logística reversa se tornou fundamental e o tema vem crescendo muito no mercado de trabalho. A Política Nacional de Resíduos sólidos aprovou e com isso, incentivou as empresas a lidarem com isso.

Os resíduos de lâmpadas fluorescentes se caracterizam por lâmpadas adquiridas, utilizadas e descartadas pelo consumidor. Normalmente, essas lâmpadas fluorescentes podem retornar ao seu ciclo produtivo, através canais reversos de pósconsumo como de reciclagem e de reuso. Com a logística reversa pós-consumo de lâmpadas fluorescente é possível retornar o resíduo descartado ao ciclo de negócios ou ao ciclo produtivo. A logística reversa já é um instrumento utilizado por diversos países como uma alternativa eficiente para o adequado gerenciamento de resíduos. No Brasil foi a PNRS que implantou este sistema. O objetivo é fazer retornar todos os produtos pós-consumo ao setor empresarial. Este retorno garante a recuperação dos materiais recicláveis que farão parte desse novo ciclo produtivo. (VG RESÍDUOS, 2018).

Segundo Passos, Arno e Folmer (2020) sobre a importância do método de logística reversa para não acarretar diversos danos:

Percebe-se a importância do recolhimento destas lâmpadas devido aos riscos à saúde e meio ambiente, através da logística reversa. Além disso fica evidente que em diversos municípios a coleta ainda não acontece de forma organizada e eficiente, o que continua ocasionando problemas e dificultando o entendimento da sociedade. A implantação deste ponto de coleta, foi importante para dar oportunidade ao consumidor de fazer sua parte na gestão compartilhada dos resíduos sólidos tão presente na Política Nacional. Verificou-se que após essa movimentação, atualmente no município já existe 3 (três) pontos de coleta de lâmpadas, o que é uma conquista, 
pois melhora as condições de qualidade de vida para toda população. (Passos; Arno e Folmer, 2020).

Meireles e Moraes (2017) em relação à logística reversa para o descarte de lâmpadas:

A logística reversa foi estabelecida como instrumento de desenvolvimento econômico e social, pela Política Nacional de Resíduos Sólidos no ano de 2010, compreendendo um conjunto de ações, procedimentos e meios destinados a viabilizar a coleta e o retorno dos resíduos sólidos ao setor empresarial após o seu consumo. As lâmpadas fluorescentes pós consumo são obrigadas a retornar aos seus fabricantes, para que providenciem a destinação final adequada. As lâmpadas são classificadas como resíduos perigosos, o descarte inadequado desse material, pode causar problemas para a saúde da população e ao meio ambiente. Uma lâmpada tem a capacidade de contaminar até 15 mil litros de água ou uma piscina inteira, devido ao mercúrio encontrado em sua composição. (MEIRELES E MORAES, 2020).

\section{RESULTADOS E DISCUSSÕES}

Para o desenvolvimento dos resultados do artigo, foi utilizado a aplicação de questionário pela plataforma Google Forms. Obteve-se o retorno de 48 respostas no total. Abaixo é apresentado os gráficos com suas respectivas respostas. Conforme figura 1:

Identifique-se:

48 respostas

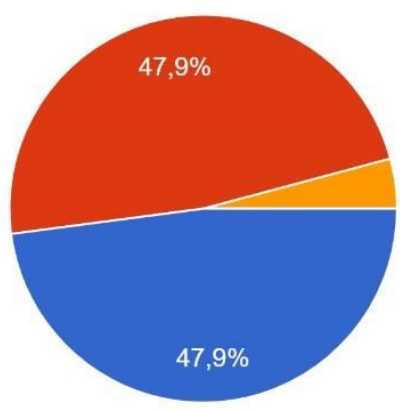

Masculino.

Feminino.

Empresa.

Prefiro não responder.

Fonte: Próprios autores. 2021.

A quantidade de entrevistados do sexo masculino e feminino foram iguais, superando as empresas que foram poucas.

Analisando o método da logística reversa na vida dos entrevistados, obteve-se o seguinte resultado, conforme a figura 2 : 
Você utiliza o método da Logistica Reversa na sua empresa/casa?

48 respostas

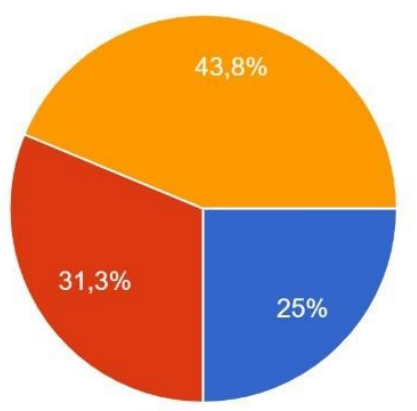

Sim.

Não.

Não sei o que é, mas gostaria de saber do que se trata.

Fonte: Próprios autores. 2021.

A maioria das pessoas $(43,8 \%)$ não conhecem o método da Logística Reversa, mas sentem à vontade de aprender mais sobre o assunto. $31,3 \%$ das pessoas não utilizam tal método e $25 \%$ das pessoas utilizam nas suas empresas/casas.

Em relação à explicação do conceito de Logística Reversa para os entrevistados, obteve-se os seguintes resultados, conforme a figura 3:

Logística reversa é a área da logística que foca no retorno dos materiais já utilizados para o processo produtivo, visando o reaproveitamento ou descarte apropriado de materiais. Sabendo do que se trata, qual é a sua opinião sobre a Logística Reversa ser benéfica ao meio ambiente?

48 respostas

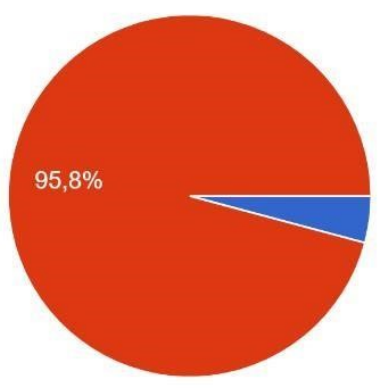

As empresas perdem seu tempo. Ao invés de produzir coisas novas, se preocupam com o reaproveitamento. Isso dará muito trabalho e poderá interferir no lucro.

É fundamental a utilização de tal método, porque se não for feito da maneira correta, pode acarretar vários fatores negativos. Nosso planeta não tem recursos infinitos e não tem espaço para tanto resíduo gerado.

Fonte: Próprios autores. 2021.

Um percentual bem elevado sabe que a Logística Reversa é benéfica ao meio ambiente e que se não for feito da maneira correta, pode acarretar vários fatores negativos. 
Apresentando as vantagens da Logística Reversa para as empresas, obteve-se os seguintes resultados, conforme a figura 4 :

Quais das alternativas abaixo são vantagens da logistica reversa?

48 respostas

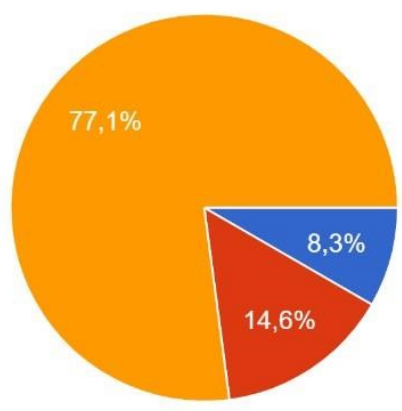

Representa um diferencial competitivo e estratégico, pois existem casos que os resíduos acabam agregando valor à operação da empresa.

Quando a empresa pratica e divulga a logística reversa, é favorecida e passa uma excelente imagem

Ambas as alternativas.

Fonte: Próprios autores. 2021.

$77,1 \%$ das pessoas sabem das vantagens da Logística Reversa para as empresas. A divulgação de tal método passa uma excelente imagem para a empresa e representa também um diferencial competitivo e estratégico entre as empresas.

Apresentando o custo para implementação, obteve-se os seguintes resultados, conforme a figura 5 :

O custo para implementar è alto?

48 respostas

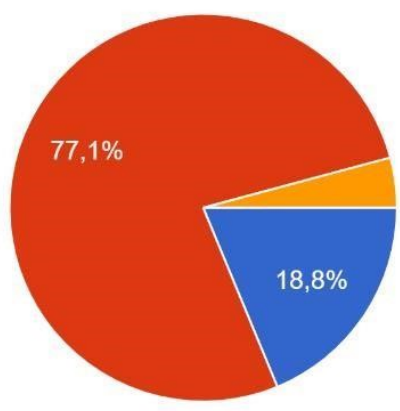

Não, pois é um processo simples e que qualquer um pode fazer de maneira rápida e fácil.

Depende muito do processo da empresa, mas em geral, não são tão baratos. A boa notícia é que podem se encontrar tratadores dispostos a comprar resíduos das empresas, fazendo com que o custo seja reduzid..

- Sim, por isso ninguém e nenhuma empresa quer praticar esse método.

Fonte: Próprios autores. 2021. 
Em relação a opinião das pessoas com o custo para a implementação, a maioria reconhece que não são tão baratos e que podem se encontrar tratadores dispostos a comprar resíduos das empresas, fazendo com que o custo seja reduzido ou até zerado.

O questionamento em relação ao lucro da prática da Logística Reversa, obteve-se os seguintes resultados, conforme a figura 6:

Há possibilidade de ganhos financeiros/lucro para as empresas praticando esse método? 48 respostas

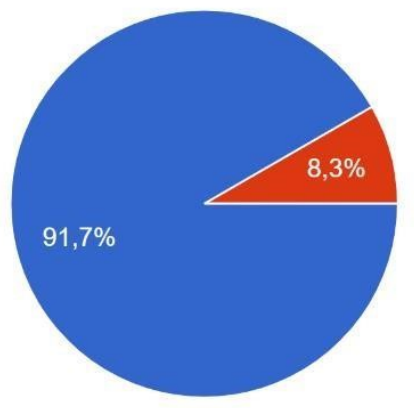

Sim, e muito. Há empresas que retiram muito valor dos resíduos dos produtos recolhidos. Existem também organizações que se especializam na prestação de serviço para empreendimentos que possuem obrigação de praticá-la.

Não, porque a empresa perderia tempo com produtos que já foram utilizados, ao invés de utilizar produtos novos.

Fonte: Próprios autores. 2021.

Um percentual bem grande dos entrevistados sabe que se pode obter lucro, ganhos financeiros com as empresas praticando esse método.

Em relação ao entendimento dos entrevistados com o término do ciclo de vida das lâmpadas, obteve-se os seguintes resultados, conforme a figura 7:

Quando o ciclo de vida útil de suas lâmpadas termina, como você faz o descarte?

48 respostas

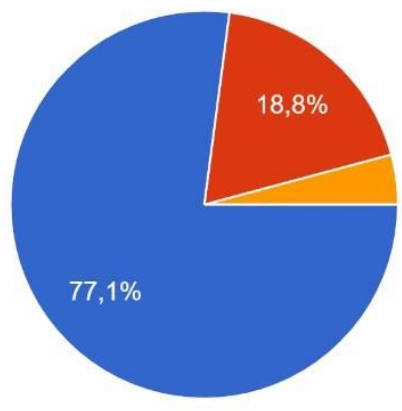

Jogo no lixo com todos os cuidados para os trabalhadores responsáveis pelo recolhimento não se machucarem.

Devolvo ao estabelecimento que comprei, para o resíduo ser utilizado da maneira correta e continuar sendo útil para alguém.

Jogo fora e não me preocupo com o destino da lâmpada.

Fonte: Próprios autores. 2021. 
A maioria dos entrevistados se preocupam com o destino das lâmpadas e as devolve ao estabelecimento da compra, para o resíduo ser utilizado da maneira correta e continuar sendo útil para alguém. Com $18,8 \%$ estão as pessoas que se preocupam com os trabalhadores responsáveis pela coleta de lixo e jogam as lâmpadas fora com todo cuidado. Uma minoria joga as lâmpadas fora e não se preocupa com o destino dela.

Analisando o entendimento das pessoas entrevistadas em relação à quebra de uma lâmpada fluorescente, obteve-se os seguintes resultados, conforme a figura 8:

Se ocorrer o imprevisto de uma lâmpada fluorescente quebrar, o que fazer?

48 respostas

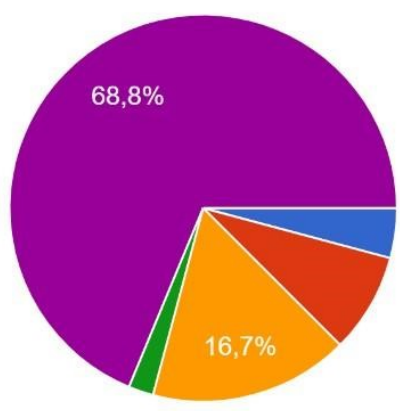

É preciso retirar as crianças e animais do ambiente, e não deixar ninguém tocar no material.

Ventilar é importante, por isso temos que abrir janelas e portas imediatame...

- Para retirar os cacos, espera a poeira abaixar (literalmente), use luvas e os...

Use fitas adesivas e papel toalha umedecido para limpar os últimos resí..

Todas as alternativas estão corretas.

Fonte: Próprios autores. 2021.

A maioria das pessoas sabem todos os cuidados que se deve ter após a quebra de uma lâmpada fluorescente.

Analisando o papel da Logística Reversa para o descarte das lâmpadas, obteve-se os seguintes resultados, conforme a figura 9:

Qual é o papel da Logística Reversa para o descarte de lâmpadas?

48 respostas

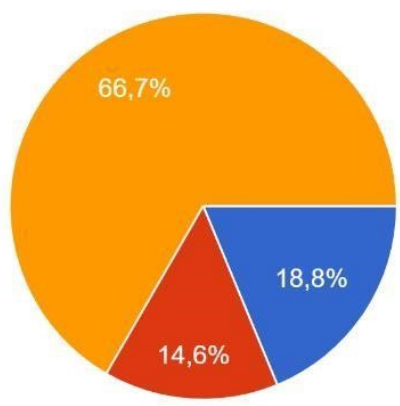

A logística reversa envolve ações pósconsumo, considerando produtos que, devido à sua composição, impactam significamente o meio ambiente quando descartadas incorretamente.

A Logística Reversa é fundamental no descarte de lâmpadas e deveria ser utilizada por todos. A conscientização dos consumidores é uma questão nobre e de muito valor.

- Ambas as alternativas estão corretas.

Fonte: Próprios autores. 2021. 

lâmpadas.

Os entrevistados sabem da importância da Logística Reversa para o descarte das

Em relação a conclusão do questionário, obteve-se os seguintes resultados, conforme a figura 10 :

Ok, vamos finalizando por aqui. Após um breve estudo, entendemos como funciona o método da Logística Reversa. Você implementaria a LR nos seus projetos/empresa e até mesmo na sua vida? 48 respostas

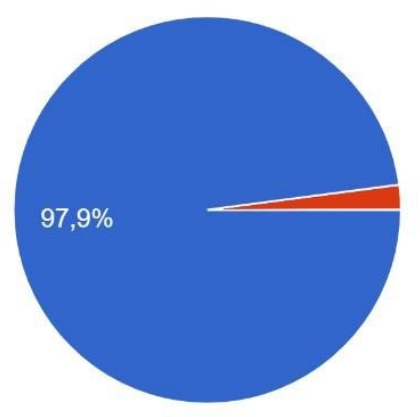

Sim, pois acho fundamental cuidarmos do nosso meio ambiente. Afinal, sem ele não somos nada.

Não, porque é um custo elevado e não daria lucro para o meu negócio.

Fonte: Próprios autores. 2021.

Diante dos resultados obtidos, a logística reversa para o descarte de lâmpadas apresenta um campo mais maduro para discussão, visto que há uma quantidade significativa de estudos disponíveis investigando seus supostos benefícios e limitações. Os resultados obtidos levam a crer na viabilidade de utilização dessa técnica.

No questionário são discutidos alguns tópicos como o conceito de tal método, vantagens, se o custo para implementação é alto, se pode obter lucros financeiros o utilizando etc.

Em relação aos perigos eminentes com a quebra das lâmpadas fluorescentes, existe um consenso dos entrevistados em entender o que se deve fazer para não dar nenhum tipo de problema.

A logística reversa é fundamental para o descarte das lâmpadas e envolve ações pósconsumo, considerando que os produtos devido a sua composição, impactam significamente de maneira negativa o meio ambiente.

97,9\% das pessoas entrevistadas implementariam a logística reversa em suas vidas/negócios. 
Uma indicação forte desse estudo é que o método apresentado deve ser implementado em vários lugares como: escolas, empresas, locais de coleta, propagandas etc. O meio ambiente é nosso lar e não pode ser danificado.

\section{CONSIDERAÇÕES FINAIS}

Diante o estudo apresentado, é notório que no Brasil há um grande consumo de lâmpadas, mas, infelizmente na maioria das vezes o pós-consumo não é devidamente correto.

Apesar do grande desconhecimento da população em relação à logística reversa, grandes empresas já vêm aderindo esse método, pois ela é a possível solução para o descarte incorreto das lâmpadas. A sua implementação é essencial num todo, porque além de trazer fins lucrativos à empresa, busca reinserir os produtos na cadeia econômica, visando diminuir o descarte e incentivar o pós-consumo consciente, além de ajudar a não poluir o meio ambiente, já que quando se fala do descarte incorreto de lâmpadas, pode trazer diversos malefícios tanto para a saúde humana, quanto para o meio ambiente. A contaminação de substâncias tóxicas para o meio ambiente, resulta em extinção de espécies, aquecimento global, entre outros vários malefícios.

Conclui- se que, é de grande importância introduzir a logística reversa no cotidiano físico e jurídico, que é necessário a estruturação de sistemas através de autoridades que possam ingerir programas coletivos para operacionalizá-la. A Política Nacional de Resíduos Sólidos introduz a divulgação desse assunto trazendo benefícios tanto para as empresas, quanto para o meio ambiente. É sugerido que exista uma interação entre essas gestões no geral quanto pública, tanto privada, visando a troca de experiências e a construção conjunta de requisitos e padrões de qualidade para todo o meio.

No estudo, obteve-se inúmeras explicações da forma como a Logística Reversa funciona e como ela é fundamental para todos. Ao aplicar o questionário, é perceptível que algumas pessoas não obtêm o conhecimento adequado em relação ao tema. Dessa forma, um dos intuitos do estudo é trazer essa informação. No decorrer do questionário, foram aumentando as explicações e os entrevistados mostraram um conhecimento mais elevado.

Contudo, o resultado obtido pelo estudo foi satisfatório. Apesar da implementação da logística reversa ser um assunto ainda prematuro, a população está mais consciente e entende que descartar corretamente é fundamental para o meio ambiente. 


\section{REFERÊNCIAS}

CAMPOS, Alexandre de; GOULART, Douglas Garcia.Logística reversa integrada: Sistema de responsabilidade pós-consumo aplicados ao ciclo de vida dos produtos. Érica/Saraiva, 2017, p.15. Disponível em: $<$ https://www.google.com.br/books/edition/ /e4uwDwAAQBAJ?hl=pt-BR\&gbpv=0 $>$. Acesso em: 05/04/2021.

LIMA, Josiane Pichani; ALVES, Ana Paula. Logística reversa pós-consumo de lâmpadas fluorescentes: uma survey online com consumidores da cidade de Osório/RS, 2017, Revista Geral Premium. Disponível em: $<$ http://sys.facos.edu.br/ojs/index.php/gestao/article/view/159/0 $>$.Acesso em: 31/03/2021.

LUDWING, Simone. Descarte de lâmpadas fluorescentes será dia 14 de dezembro, 2018, Prefeitura Municipal de Feliz. Disponível em:

$<$ https://www.feliz.rs.gov.br/web/noticia/1979/descarte-de-lampadas-fluorescentes-sera-dia14-de-dezembro $>$. Acesso em: 31/02/2021.

MEIRELES, Jaqueline Fernanda; MORAES, Alessandra Ribeiro de. Logística reversa de lâmpadas na prática: um estudo de caso no município de Mundo Novo/MS, 2020.

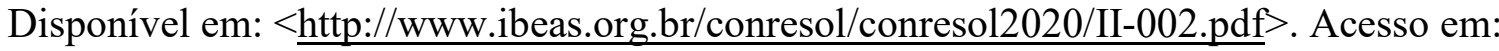
03/04/2021.

MENDES, Henrique Manoel Riani. Análise de experiências internacionais com a logística reversa de eletroeletrônicos: comparação com a realidade brasileira e recomendações, 2017. Disponível em: $<$ https://www.slideshare.net/HenriqueMendes1/anlise-de-experinciasinternacionais-com-a-logstica-reversa-de-eletroeletrnicos-comparao-com-a-realidadebrasileira-e-recomendaes $>$. Acesso em: 30/02/2021.

MINISTÉRIO DO MEIO AMBIENTE, Decreto regulamenta logística reversa, 2017. Disponível em: $<$ https://www.gov.br/mma/pt-br/noticias/noticia-acom-2017-10-2640 $>$. Acesso em: 04/04/2021.

NOVAES, Nathalia; MORASSI, Natália. Descarte de lâmpadas, como fazer corretamente? 2020. Disponível em: $<$ https://zenitdesign.com.br/descarte-de-lampadas/> . Acesso em: 05/04/2021.

OCHOA, Carlos. Amostragem probabilística: Amostra aleatória simples, 2015. Disponível

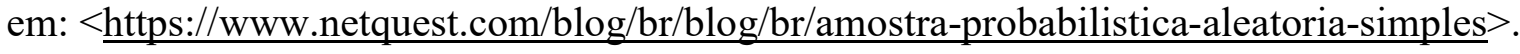
Acesso em: 30/05/2021.

PASSOS, Manuela Gazzoni dos; ARNO, Lucas; FOLMER, Diana.Avaliação da logística reversa de lâmpadas fluorescentes de um estabelecimento comercial no município de Chapecó, SC após a instalação de um ponto de coleta,2020. Disponível em: $<$ http://www.ibeas.org.br/conresol/conresol2020/II-003.pdf $>$. Acesso em: 05/04/2021.

SINIR, Logística Reversa, 2021. Disponível em: $<\underline{\text { https://sinir.gov.br/logistica- }}$ reversa\#: : :text=A\%20Log\%C3\%ADstica\%20Reversa\%20\%C3\%A9\%20um,ciclos\%20produ tivos $\% 2 \mathrm{C} \% 20 \mathrm{ou} \% 20$ outra $\% 20$ destina $\% \mathrm{C} 3 \% \mathrm{~A} 7 \% \mathrm{C} 3 \% \mathrm{~A} 3 \mathrm{o}>$. Acesso em: 31/02/2021. 
VG RESÍDUOS, Como funciona a logística reversa pós-consumo de lâmpadas

fluorescentes? 2018. Disponível em: $<$ https://www.vgresiduos.com.br/blog/como-funcionaa-logistica-reversa-pos-consumo-de-lampadas-fluorescentes/>. Acesso em: 28/03/2021. 